\title{
Community Participation on Soil and Water Conservation in Centeral Gondar Zone, Takussa Woreda, the Case of Kurabas Kebele
}

\author{
Fekadie Bazie Enyew \\ Department of Geography and Environmental Studies, Kebri Dehar University, Korahey zone, Somali Regional State, Ethiopia.
}

How to cite this paper: Fekadie Bazie Enyew. (2022) Community Participation on Soil and Water Conservation in Centeral Gondar Zone, Takussa Woreda, the Case of Kurabas Kebele. Journal of Humanities, Arts and Social Science, 6(1), 85-97. DOI: $10.26855 /$ jhass.2022.01.010

Received: January 18, 2022

Accepted: February 15, 2022

Published: March 3, 2022

${ }^{*}$ Corresponding author: Fekadie Bazie Enyew, Department of Geography and Environmental Studies, Kebri Dehar University, Korahey zone, Somali Regional State, Ethiopia.

Email: fekadiebazie03@gmail.com

\begin{abstract}
A number of soil and water conservation methods were introduced. Consequently, the government has invested in sustainable soil and water conservation (SSWC) measures. This study was Conducted in Central Gondar Zone, Takussa Woreda, the Case of Kurabas Kebele which is typically high potential for producing maize and cereal crops and mixed farming, in the Northwestern high lands of Ethiopia. The objective of the study was to assess the community-based soil and water conservation practices and to evaluate how well implemented measures address to specification and to describe tradition and improved concentration measure, surrey questionnaire was administered to 98 randomly selected farmers from study area and 4 respondents for interview and 2 focus group discussion were purposively selected. To achieve this goal descriptive research design with survey method was as useful for study. To address the stated objective both quantitative and qualitative data were collected. According to the findings different erosion controlling measures such as terracing, traditional water way, grass strip and planting trees have been implemented by farmers in the study area. However, the efforts made by farmers to control soil erosion were found to be in constant in efficient, the study shows that existence of soil water conservation in study area was identified by indicators like existence of gullies, reduction in soil capacity to grow crops and prevalence of barren land. The major cause for soil erosion was, poor farming practice, over cultivation and improper utilization of land which could result from deforestation and small land holding size. Regarding the awareness and perception of the community most farmers were aware of crop rotation following, terracing construction and planting trees But, because of different factors affecting to implement them include education, lack of training, small land holding size and socio-economic problem. Based on the findings the researcher was listed some recommendations to prevent the problems such as, the degradation depletion of soil, water and plants affects the livelihood of community because of this community must participate soil water conservation practice to solve the problem, the lasting solutions to the problem of soil erosion should include minimizing population pressure and development of the other sectors of economy and involvement of the local people.
\end{abstract}

Keywords

Community, conservation, livelihood, soil erosion 


\section{Introduction}

\subsection{Back ground of the study}

Soil erosions is removal of top soil faster than soil forming possess can replaces it. A cording to Triadic and sigh (2002), removal of sol, from one part to another usually sown hill by the action of water, soil erosion is a particular physical process that cause land and soil degradation, and refers to the wearing a way of the land surface by water and/or winds as well as the redaction in soil productivity due to physical loses of top soil, reduction in rooting depth removal of plant nutrients and loss of water Mahmud (2005).

High erosion rates throughout Africa's are Associated with poor vegetation cover in crop land, rangeland or forest land, soil erosion is acceleration by high amount/or intercity of rainfall, steep slopes, un stable geomorphologic events and human impacts like deforestation, over grazing, burning and shifting cultivation.

The loss of soil either by natural or by miss management, it is harmful not only for Agricultural development but to the whole ecosystem therefore, its conservation was now becoming a matter of grave concern. According to Mesfine (1998), people are dependent on soil and conserve good soil is dependent on people who use land wisely. For counties like Ethiopia, whose economy is dominantly agrarian. The concern of soil resources draws the attention of governmental and nongovernmental agencies. The forces of nature often destroy soil caver of areal. The destruction of soil cover is described as soil erosion Kumar (2002). According to Daniel wide range of programs encouraging community participation in conserving and protecting soil, water and other natural resources and also local citizens the ability to work on conservation problem at local level. The community constitutes are farmers, home owners, water shade organization, environmental groups, developers, youth, local business, Civic organization, and other interested in conservation.

Now a day, many communities worldwide face serious environmental degradation, including deforestation, overgrazing, soil erosion, overexploitation of biodiversity and water pollution problems which are certainly resulted from all associated with mismanagement of natural resources (Gomeje, 2014). In fact, soil erosion is now one of the most widely spread environmental problems facing at globally (David, 2006). Soil erosion in associated with inappropriate land management practices is one of the main factors causing degradation. Poor soil water conservation practices and lack of effective planning and implementation approaches for soil conservation are responsible for accelerating degradation on agricultural lands and siltation of lacks and reservoirs down streams. Most soil and water conservation planning approaches rely on empirical assessment methods by experts and hardly consider farmers knowledge of soil erosion. Conservation program relied on coercive approaches and performed poorly (Yohannis, 2000).

Ethiopian agriculture and the livelihood of rural community have been affected by land degradation the major drivers of which are soil erosion and deforestation. Soil erosion depletes soil fertility and reduces land productivity which in turns reduces the farm level income of households. Reduction in fertility of soil results in poor water holding capacity of the soil and vegetative growth of crops are limited as result particularly during decrease in the Kasu, 2011.

The practice of community development is not new in Ethiopia's society. Ever before the advent of colonial administration, various communities in Ethiopia have employed communal efforts as mechanism for mobilizing community resources and for providing physical improvement and functional facilities in their given localities to further their social, political and economic interest.

Proper implementation and evaluation of the implementation of the community participation in Soil and water conservation and the periodic or regular overall impact assessment of the program is important to measure its effect on improving the livelihood of the community and reclamation of the environment. In this regard, it is essential to have relational databases on soil, climate, crop yields, land use and the social and economic conditions prevailing in the communities (ARMRD-PCARRD, 1998). The fundamental question however is the establishment of indicators and database. These data need to be regularly collected from experimentation community, field surveys and monitoring of farm and SWC systems, (Gabremedin, 2004; Fikiru, 2009) have been done on the issue related to community based sustainable soil and water conservation management focuses on different regional state of the country and the so far identified socio-economic and cultural factors by other researchers in other case areas may be different from the study area under consideration. Because it is obvious that people in different societies have different cultural elements, other social value and belief system. In this regard, one of the main reasons for conducting this 
research in Kurabas kebele, Takussa Woreda is to assess the awareness and perception, participation and root causes of the participatory problem.

\section{Research Methodology and Description of the Study Area}

\subsection{Location}

The study was conducted in kurabas kebele, Takussa Woreda in central Gondar zone of Amhara national regional state. It is located $780 \mathrm{~km}$ far from Addis Ababa the capital city of Ethiopia and 30km west of lake tana, the largest lake in Ethiopia and its absolute location lies at $12^{0} 6^{\prime} 00^{\prime \prime}$ to $12^{0} 12^{\prime} 00^{\prime \prime} \mathrm{N}$ (latitude) and $36^{0} 53^{\prime} 00^{\prime \prime}$ to $37^{0}$ 00’00” E (longitude) with the elevation from 1,467-2,052 masl (Ethiopia Mapping Agency, 2020).

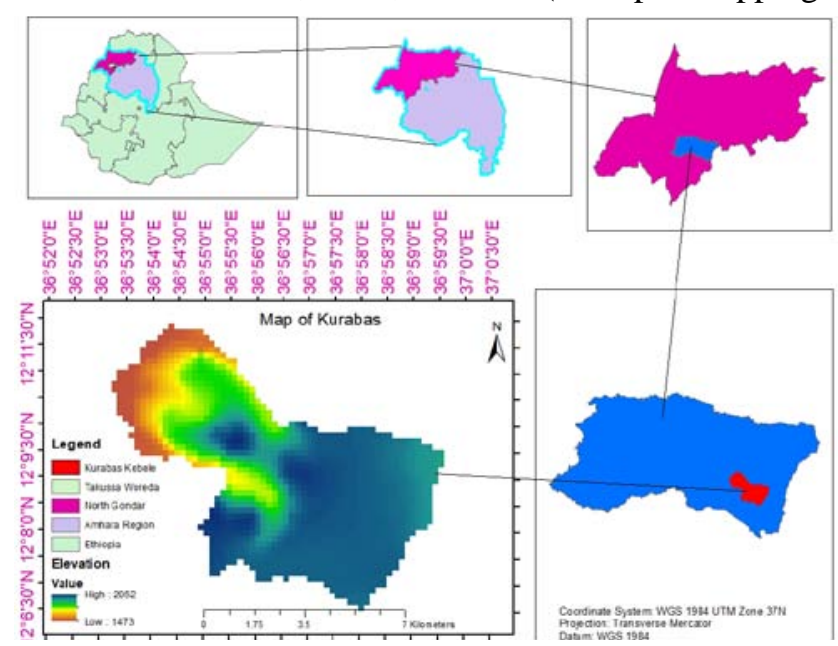

Figure 1. Study area map.

\subsubsection{Topography}

Topographically, the kebele characterized by undulating terrain with significant latitudinal variation. It has the highest and the lowest elevation. The highest elevation of the kebele is 2,052 masl and the lowest elevation of the town is 1,467 masl. It is characterized by plain and undulation (plateau) land form with topography of $66 \%$ undulation, $20 \%$ plain, $14 \%$ of rock land surface (Takussa woreda administrative office, 2020).

\subsubsection{Climate and vegetation}

Kurabas kebele is located in the tropical climate type which receives seasonal rainfall and characterized by Woinadega climate zone with the mean annual rainfall of $1,553.3 \mathrm{~mm}$ per year and the mean daily temperature is $15^{\circ} \mathrm{C}$ (Meteorology Agency, 2018). About 25\% of total land area is covered by vegetation or forests.

\subsection{Demographic and socio-economic characteristics}

\subsubsection{Population}

Based on 2007 national census conducted by central statistics agency of Ethiopia, the total population of the kebele was 11,222 from which 5,619 were males and 5,603 were females.

\subsubsection{Socio-economic activity}

The economic activity of the Kurabas kebele is dominated by mixed farming agricultural system i.e., raising of crops and rearing of livestock. The main social structure of the town mainly Amhara (99\%), other ethnic groups made up of the population. The majority of the inhabitants follow Ethiopian Orthodox Christianity with 99\%, while $1 \%$ are Muslim community and the remaining are other part of ethnic group of the population (kurabas kebele administrative office, 2020).

\section{3 research design}

The research was conducted using descriptive methods of statistics in which figures, percentage and tables were used. The study is following a cross-sectional of the population this is because it reduces time and money wastage. 


\subsubsection{Sample technique}

The researcher was used both sample techniques i.e., probability and non-probability sampling technique. From the probability sampling technique, the investigators used simple random and systematic technique and from non-probability sampling purposive sampling technique may use. The reason why used simple random probability sampling technique is to minimize the bias and in order to give equal chance for every community who live in the study area.

\subsubsection{Sample size}

In the study area, according to the recent data, there were about 11,222 total populations. From this, 4,655 are households, from the total house hold determining 98 respondents were select as a sample by using (Yamen formula, 1967).

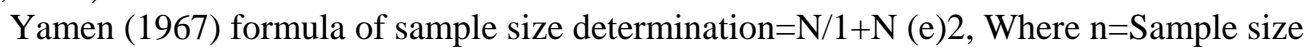

$\mathrm{N}=$ Total house hold

$\mathrm{e}=$ Level of precision $(10 \%)$

So, $\mathrm{n}=4655 / 1+4655(10 \%) 2$

$=4655 / 1+4655(0.1) 2$

$=4655 / 1+4655(0.01)$

$=4655 / 1+46.55$

$=4655 / 46.55$

$=97.8 \sim 98$

\section{4 source of data}

Both primary and secondary were generated by employing quantitative and qualitative methods.

The quantitative methods involve the use of house hold survey while qualitative methods used includes focus group discussion, key information interview of this research the primary data was collected through questionnaire and interview. Secondary data were gathered from different official documents, internet, and other published materials.

\subsubsection{Instrument of data collection}

\section{(1) Questionnaire}

A questionnaire which includes both open and closed ended questions was applied. The questionnaire was prepared in English language; however, it was translated to the local language in order to make questions sampled and clear to the samples. This helped the researcher to see whether there are any difficult in relation the questionnaire and to modify based on the feedback of pretest or to check the reliability of the data which is going to collect.

\section{(2) Interview}

Interview also administered by the investigator to generate information, community-based soil and water conservation, measures to be taken to ensure the problem. The data were collected mainly by using direct data method. Both closed and open questions are used, open questions are those explain questions while closed ended are those yes/no, multiple choice and true, false.

\section{(3) Focus group discussion (FGCD)}

Focus group discussion was carried out to explore the knowledge and practices or participation of community in soil and water conservations.

\section{(4) Observation}

Direct field observation encompassed visit of cultivated and uncultivated land, topography, vegetation cover, settlement pattern and the over all aspects of soil and water conservation practices of the study area.

\subsection{Method of data collection}

The data were collected mainly by using direct data collection method. This includes questionnaires, interview, and survey method. Both open ended and close ended type of questionnaire were used. Open ended includes those explained questions and closed ended includes yes, no questions, true false, and multiple choices. 


\subsubsection{Methods of data analyze and presentation}

To make analyze first, the researcher edited the data which were collected by the questionnaire, interview, filed observation and focus group discussion, editing is done to detect error and omissions and to correct these when possible. Secondly coding, i.e., assigning numerals, or other symbols to the data so that response put in to limited number of categories. Thirdly, classifying data having common characterizes to one class and in this way the entire data get divided into groups. Finally, the arranged data were processed in the form of statically table for analytical purpose or interpretation. The data generated by the house hold survey were statically analyzed using frequencies, descriptive and the chi-squares (2) static is preformed to test significance of relationships between farmers adoption of soil and water conservation and various house hold characteristics such as age, level of education, family size, size of land holding and other variables, and analyze the collected data by using SPSS software.

\section{Data Analysis and Interpretation}

This part of the paper deals with the resent and discussion of the data gathered from sample responds.

\subsection{Back ground of the respondents}

\subsubsection{Age-sex distribution of sample household}

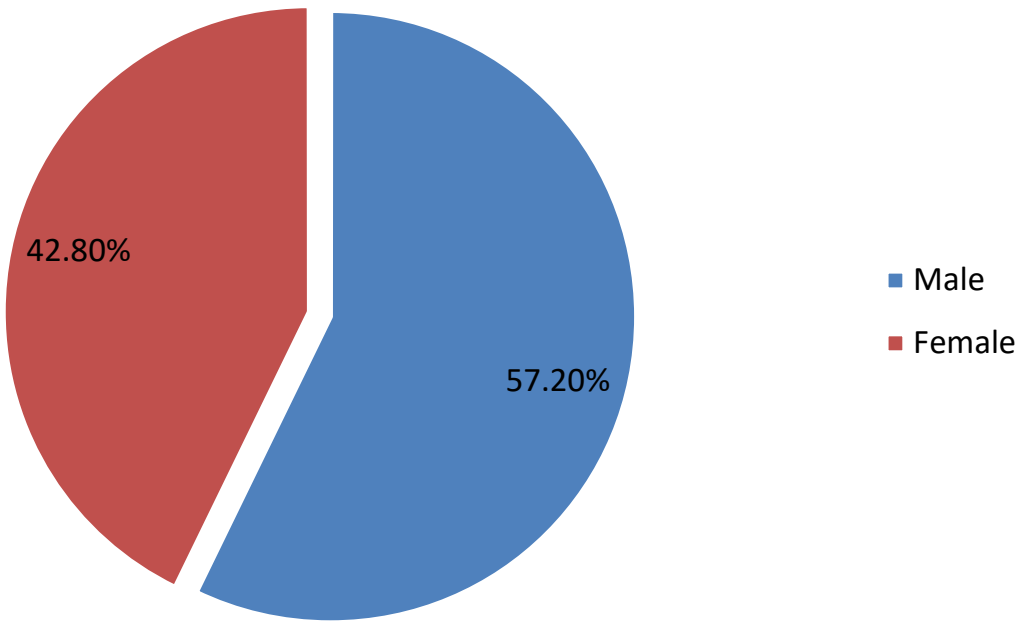

Source Field survey, 2020

Figure 2. Age-sex composition.

According to Figure 1, the majority of sample populations (57.2\%) were male, while the remaining (42.8\%) were females. This shows that the sample population or dominated by male.

\subsubsection{Marital Status of sampled household}

Table 1. Marital status of sampled household

\begin{tabular}{ccc}
\hline Marital status & Number & Percentage (\%) \\
\hline Married & 64 & $65.3 \%$ \\
Single & 20 & $20.4 \%$ \\
Divorced & 6 & $6.1 \%$ \\
Widowed & 8 & $8.2 \%$ \\
Total & 98 & $100 \%$ \\
\hline
\end{tabular}

Source: Field survey, 2020 
As Table 1 shows the majority of the respondents (65.3\%) are married. On the other hand, single participant in soil conservation comprise (20.4\%) and $8.2 \%$ are widowed, so they can be participation of the sample respondents, while $(6.1 \%)$ are divorced, so they can be participating in soil conservation.

\subsubsection{Education Status of respondents}

Like most of the kebele people, the sampled households in access to education. Hence, the majorities attended primary education Level and some are composition of secondary education as shown on bar graph below.

Table 2. Educational status of educational sampled house hold

\begin{tabular}{ccc}
\hline Level & Number of respondents & Percentage \\
\hline Can't read and write & 26 & $26.6 \%$ \\
Can read & 33 & $33.7 \%$ \\
Primary school & 21 & $21.4 \%$ \\
Secondary school & 12 & $12.2 \%$ \\
Tertiary school & 6 & $6.1 \%$ \\
Total & 98 & $100 \%$ \\
\hline
\end{tabular}

Source: survey. 2020

As the Table 2 indicates that $26.6 \%$ of the respondents were can't read and write have no any school experience, $33.7 \%$ of them have got chance of reading and writing in the first circle education, $21.4 \%$ respondents have got attended primary school and $12.2 \%$ of them have go computed secondary school and also $6.1 \%$ of the respondents have got chance of tertiary school. This implies that a great majority of sample house hold heads have low level of Education.

Table 3. Livestock owed by sample of house hold

\begin{tabular}{|c|c|c|}
\hline Livestock types & Number & Percentage (\%) \\
\hline Goats & 21 & $21.4 \%$ \\
\hline Sheep & 24 & $24.5 \%$ \\
\hline Horse & 1 & $1 \%$ \\
\hline Donkey & 19 & $19.4 \%$ \\
\hline Cow & 33 & $33.7 \%$ \\
\hline Total & 98 & $100 \%$ \\
\hline
\end{tabular}

Source: Field survey, 2020

However, focus group discussion participants stated that the number of livestock increased at the village level. Livestock increase at village level. Livestock increase has an important implication on degradation of communal grazing lands (Belayneh, 2005). This is negative impact on SWC. Because of over grazing land, destroying conservation such as water ways, stone bunds.

Table 4. Land holding size (hec) of the sample Respondent

\begin{tabular}{ccc}
\hline Categories & number & Percentage (\%) \\
\hline $1-2$ & 24 & $24.5 \%$ \\
$2-3$ & 36 & $36.7 \%$ \\
$3-4$ & 15 & $15.3 \%$ \\
$4-5$ & 18 & $18.4 \%$ \\
$5-6$ & 4 & $4.1 \%$ \\
$>6$ & 1 & $1 \%$ \\
Total & 98 & $100 \%$ \\
\hline
\end{tabular}

Source: Field survey, 2020 
Regarding Land ownership Table 4 almost all of the Farmers have their own land. From the sampled households, 24.5\% posses 1-2 hectares of land, 36.7\% had land Area between one and two hectors, $15.3 \%$ had between hectors. Some/most of agricultural land in study area has so far been such divided to smallest land.

Table 5. Farmers' income from their area

\begin{tabular}{ccc}
\hline Categories & Number & Percentage (\%) \\
\hline Low income & 12 & $12.2 \%$ \\
Medium & 71 & $72.5 \%$ \\
High income & 15 & $15.3 \%$ \\
Total & 98 & $100 \%$ \\
\hline
\end{tabular}

Source: Field survey, 2020

According to Table 5, about $15.3 \%$ of respondents' high income from their own farm lands \& in their livestock raring of animals. Most of the respondents in study area has medium income, about $72.5 \%$ encourages their income \$12.2 \% indicates the low-income level. This shows that most of farmers are good and best level of income and no any negative in their living way of life.

\subsection{Level of erosion in different land use}

Soil erosion is generally occurring when the soil is displaced by rain fall which is considered as the driving factor of soil erosion.

The sampled Respondents were also asked about the intensity of soil erosion in different land use categories.

Table 6. Land use types of the study area

\begin{tabular}{cccc}
\hline Land use & Level of soil erosion & Number of respondents & Percentage (\%) \\
\hline Pastoral land & Medium & 26 & $26.6 \%$ \\
Farm land & High & 61 & $62.2 \%$ \\
Forest Land & Low & 11 & $11.2 \%$ \\
Other & & - & - \\
Total & & 98 & $100 \%$ \\
\hline
\end{tabular}

Source: Field survey, 2020

According to Table 6, about $62.2 \%$ of respondents agreed that soil erosion is high on postural land but for (26.6\%) of soil erosion is high on farm land while about (11.2\%) of households agreed that soil erosion is less on forest land. Generally, this shows that the intensity of soil erosion higher on farm land than the other land.

Table 7. Major Constraints of SWC

\begin{tabular}{ccc}
\hline Constraints & Number of respondents & Percentage (\%) \\
\hline Lack of equipment & 23 & $23.5 \%$ \\
Loss of attention & 31 & $31.6 \%$ \\
Very high rain fall & 20 & $20.4 \%$ \\
Topography & 24 & $24.5 \%$ \\
Total & 98 & $100 \%$ \\
\hline
\end{tabular}

Source: Field survey, 2020

In this table, $24.5 \%$ of respondent replied that topography is the major constraint of soil and water erosion among local community, for 20 (20.4\%) respondents replied rain fall is very high in the study area. and other remaining $31.6 \%$ and $23.5 \%$ replied loss of attention and lack of equipment respectively. 
Table 8. Cause of soil erosion identified by respondents

\begin{tabular}{ccc}
\hline Cause of soil erosion & Number of respondents & Percentage (\%) \\
\hline Deforestation & 30 & $30.6 \%$ \\
Over grazing & 10 & $10.2 \%$ \\
Over cultivation & 8 & $8.2 \%$ \\
Steep farming & 22 & $22.4 \%$ \\
High rain fall & 16 & $16.3 \%$ \\
Topography & 12 & $12.3 \%$ \\
Total & 98 & $100 \%$ \\
\hline
\end{tabular}

Source: Field survey, 2020

According to the respondents, soil erosion in the study area is caused by different Factors.

Accordingly (30.6\%) of respondents replied that deforestation is cause of erosion on the other hand about (22.4\%) of them responded steep farming (12.3\%) of respondents responded topography and the remaining (16.3\%) of them high rain fall and the remaining $8.2 \%$ (over cultivation) and $10.2 \%$ (over grazing) were considered as the cause for soil erosion.

The main cause of soil erosion is to rapidly increasing human population. The limited area of fertile flat lands, deforestation and excessive livestock population (Girma, 2001) cultivation of steep slopes and clearing of vegetation has accelerated erosion on the high land.

According to the respondents, the major causes of SWC erosion in study area are deforestation, over grating, over cultivation, steep farming, high rain fall and topography.

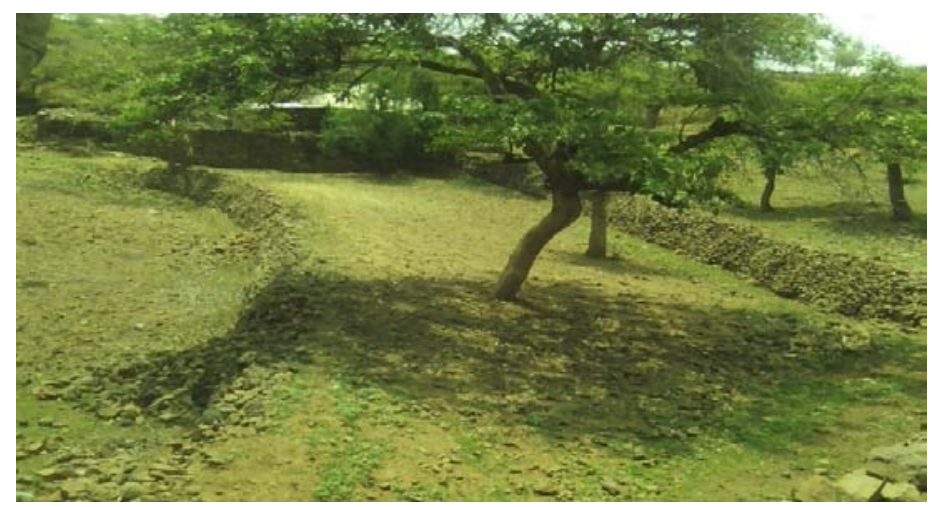

Figure 3. Soil stone bund conservation.

Table 9. The Awareness of respondents on SWC practice

\begin{tabular}{cccc}
\hline No & Practice & Number & Percentage (\%) \\
\hline 1 & Mixed cropping & 21 & $21.4 \%$ \\
2 & Terracing & 29 & $29.6 \%$ \\
3 & crop rotation & 21 & $21.4 \%$ \\
4 & Fallowing & 10 & $10.3 \%$ \\
5 & counter plowing & 9 & $9.2 \%$ \\
6 & Agro force forestry & 3 & $3.1 \%$ \\
7 & A forestation & 8 & $8.2 \%$ \\
& Total & 98 & $100 \%$ \\
\hline
\end{tabular}

Source: Field survey, 2020

The results presented in Table 9 indicates that above $21.4 \%$ of respondents are practicing mixed farming effective and measures in improving crop land productivity and crop rotation followed by $21.4 \%$. The farmers preferred 
mixed farming system and crop rotation practice due to small land holding and large family size. Secondly, it is important for soil fertility of land and it is utilized to get different of crop at a time.

In this study area, most of the farmers get training on soil and water conservation. About $76.5 \%$ of the samples respond ants got training on soil water conservation applications and $23.5 \%$ get less soil and water conservation training. Giving training on soil and water conservation measure and improves the relationship between farmers and encourages them to implement new conservation measures.

Table 10. Respondents household that get training on SWC

\begin{tabular}{ccc}
\hline Do you get training on SWC? & Number of respondents & Percentage (\%) \\
\hline Yes & 75 & $76.5 \%$ \\
No & 23 & $23.5 \%$ \\
Total & 98 & $100 \%$ \\
\hline
\end{tabular}

Source: Field survey, 2020

Table 11. Farmers practice on SWC

\begin{tabular}{ccc}
\hline Do you Practice on SWC? & Number of respondents & Percentage (\%) \\
\hline Yes & 88 & $89.8 \%$ \\
No & 10 & $10.2 \%$ \\
Total & 98 & $100 \%$ \\
\hline
\end{tabular}

Source: Field survey, 2020

In the above, farmers get training on soil and water conservation. About $89.8 \%$ of the sample respondents are get training on SWC applications and 10.2\% Households are not getting SWC (Soil Water Conservation) training. Farmers who have no access to training have gained experience from their neighbors and traditionally from their elders. Moreover, giving training on soil conservation measure improves the relationship between farmers and encourages them to implement new conservation measure. As the model farmers stated that the training must not depend only on modern expert, but experts should provide awareness on traditionally practiced ones, because of latter ones served as ground for the effectiveness of former ones in terms of creating awareness and addressing the important of soil conversation measure in controlling erosion and enhancing soil moisture. Moreover, focused group discussion stated that the time, which development agents stay on their respective working area, was very few.

Table 12. Most measure soil water conversation practice

\begin{tabular}{ccc}
\hline Types of conversation practice & Number of respondents & Percentage (\%) \\
\hline Soil bund & 13 & $13.3 \%$ \\
Cut off drain & 2 & $5 \%$ \\
Terrace & 11 & $57.1 \%$ \\
Check dams & 16 & $11.2 \%$ \\
Planting & 98 & $16.4 \%$ \\
Total & & $100 \%$ \\
\hline
\end{tabular}

Source: Field survey, 2020

AS shown in Table 12, about $57.1 \%$ terracing was constructed by public participation in the study area. This is an embankment constructed by throwing the soil dug from basin to uphill and the aim of practices is to reduce and stop erosion and increase water holding capacity of the soil so, as to enhance crop yield. The aim of stone bands is prevention of their accumulation of runoff water along the slop, colluviation and decrease of slop steepness.

\subsubsection{Cut off drains}

Are one of the physical structures constructed by digging the soil deep in order to divert the run off before reaching farm land? The farmer constructed such structures to prevent loss of seeds, fertilizer and soil due to excessive run off coming from up lands and dispose excess of water for the filed. 


\subsubsection{Check dames}

Check dames are soil and water conservation structure which are constructed with mix of medium and large size stones. The length of check dames depends on the width of farm plot. In study area, this structured mostly constructed on plot located between hills with purpose of protecting the formation of gullies. It requires more time and labor. Construction of check dames are used on farm plot where the use of other types of soil and water conservation structure is not effective. Nowadays, creation of awareness among community supported the gully rehabilitation and construction of check dames in the community roads and in farm fields is widely used. Therefore, check dames is the most effective practice of adaption of soil and water conservation measure that helps to plug gully and wetness of soil.

Table 13. SWC practice by the respondents

\begin{tabular}{ccccc}
\hline Physical soil water conservation (SWC) & Yes & Percentage (\%) & No & Percentage (\%) \\
\hline Stone band & 4 & $4 \%$ & 15 & $15.1 \%$ \\
Traditional check dam & 13 & $13.3 \%$ & 10 & $10 \%$ \\
Furrow & 3 & $3 \%$ & 28 & $28.3 \%$ \\
Terracing & 24 & $24.7 \%$ & 30 & $30.7 \%$ \\
Water way & 5 & $5 \%$ & 20 & $20.2 \%$ \\
Biological SWC & - & - & - & - \\
Planting trees & 9 & $9 \%$ & 23 & $23.3 \%$ \\
Area closure & 3 & $3 \%$ & 14 & $14 \%$ \\
Agro forestry & 14 & $14.4 \%$ & 22 & $22.2 \%$ \\
Afforestation & 16 & $16.6 \%$ & 20 & $20.2 \%$ \\
Grasse strip & 8 & $8 \%$ & 3 & $3 \%$ \\
Total & 98 & $100 \%$ & 98 & $100 \%$ \\
\hline
\end{tabular}

Source: Field survey, 2020

According to table 13, SWC practice was implemented by the household heads. Followed by terracing 30.7\%, $28.3 \%$ of the respondents practice fallowing, $20.2 \%$ uses water way and the remaining practices are implemented in the study area. The most widely implemented physical measures were stone band. On moderately sloping areas, the farmers construct soil bands for erosion control. On steep eroded bare lands, stone terrace are most used structure in study area. Stone bunds are the effective in erosion control as stated in key information.

Table 14. Farmers perceived impacts of soil SWC measures

\begin{tabular}{ccccc}
\hline What SWC can influence & Yes & Percentage (\%) & No & Percentage (\%) \\
\hline Prevent soil erosion & 28 & 28.7 & 13 & $13.3 \%$ \\
Improved soil fertility & 25 & 25.4 & $78.4 \%$ & $7.1 \%$ \\
Increased crop yield & 27 & 27.6 & 60 & $61.2 \%$ \\
Improve soil water retention & 18 & 18.3 & 98 & $100 \%$ \\
Total & 98 & $100 \%$ & & 7 \\
\hline
\end{tabular}

Source: Field survey, 2020

AS shown in Table 16, the farmers perceived that soil water conservation measures increased crop yield and the majority of farmers perceived that it prevents soil erosion and improved soil water retention capacity of soil. But, small numbers of farmers $18.4 \%$ believed that SWC measures cannot increase activity. $25.4 \%$ of the farmer's perceived SWC can improve soil fertility; only $18.4 \%$ respondents replayed that SWC can not improve soil fertility. $28.7 \%$ and $18.3 \%$ farmer perceived that SWC can prevent soil erosion and improve water retention capacity respectively. 
Table 15. Participation of Respondent in SWC

\begin{tabular}{|c|c|c|c|c|}
\hline Witness of farmers in SWC work & Yes & Percentage (\%) & No & Percentage (\%) \\
\hline Voluntary & 73 & 75 & 11 & $11.2 \%$ \\
\hline Forced & 19 & 19 & 82 & $83.7 \%$ \\
\hline Other & 6 & 6 & 5 & $5.1 \%$ \\
\hline Total & 98 & $100 \%$ & 98 & $100 \%$ \\
\hline
\end{tabular}

Source: Field survey, 2020

Table 15 shows that farmer's participation in SWC activities that were being carried out of $75 \%$ of participated in SWC works on their own field. The remaining 19\% of and above house holders asserted that soil participated simply because of they were forced to do.

Table 16. Farmer's participation on the degree of severity of soil erosion before conservation

\begin{tabular}{cccc}
\hline Variables & Number of respondents & Percentage (\%) \\
\hline Low & 8 & $8.2 \%$ \\
Medium & 35 & 55 & $35.7 \%$ \\
High & 98 & $56.1 \%$ \\
Total & $98 \%$ & $100 \%$ \\
\hline
\end{tabular}

Source: Field survey, 2017

According to Table 16, 56.1\% of the farmers replied that there was severity of soil erosion on their lands and only $8.2 \%$ of them indicated that there is no erosion problem on their farmlands. All interviewed agreed that there is severe degree of soil erosion on their lands. A regardless of their gentle slope land farmers has good perception of severity of soil erosion. House hold profiles land holding and occupation and the socioeconomic connections of the farmers in the study area is more or less similar, But their certain physical futures variations.

Table 17. Farmer's response on problems related to modern SWC

\begin{tabular}{cccccccccc}
\hline & \multicolumn{2}{c}{ Soil and stone band } & \multicolumn{2}{c}{ Agro forestry } & \multicolumn{3}{c}{ Application manure } & \multicolumn{2}{c}{ Water way } \\
Problems related to practice & Yes & No & Yes & No & Yes & No & Yes & No \\
\hline Require large labor & 32 & 11 & 55 & 20 & 43 & 11 & 34 & 22 \\
Reduce farm land size & 22 & 33 & 15 & 8 & 7 & 13 & 20 & 23 \\
Difficult to implement & 18 & 14 & 10 & 30 & 25 & 23 & 14 & 18 & 21 \\
Lack of finance & 15 & 23 & 10 & 20 & 10 & 24 & 5 & 14 \\
Lack of knowledge and skill & 11 & 17 & 8 & 20 & 6 & 98 & 98 & 98 \\
\hline Total & 98 & 98 & 98 & 98 & 98 & & 98 &
\end{tabular}

Source: Field survey, 2020

Participants of the focus group desiccation reported that the earlier soil water conservation approaches had significant impact on contemporary activities of soil conservation. Many farmers were compiled to participate in the food for the work conservation programs implemented in the 1980 and consequently failed to maintain physical structure adequately. As noted by farmers, structural soil conservation measure, it requires large labor, reduce farmer forest, difficult to implement and obstacle oxen plough. Accordingly, their preferred to practice traditionally known soil water conservation measures. And other fertility in heritance methods, like crop residues on field, because this are less expensive and diamonds little labor, might not obstacle oxen plough and make movement easier.

Lack of proper implementation and follow up of management structures were the main of obstacles to reduce the rate of soil erosion. The majority of peasants have revolved against the acceptance of modern technology (Eyasu, 2002). 
Table 18. Types of soil erosion control measures being practiced in study area

\begin{tabular}{cccc}
\hline Types of conservation practice & Unit & Area coverage (Number) & Participants \\
\hline Soil band & KM & 40 & $>50$ \\
Cut off drain & KM & 20 & $<30$ \\
Check dame & KM & 45 & $40-50$ \\
\hline
\end{tabular}

Source: field survey, 2020

\section{Conclusion and Recommendation}

\subsection{Conclusion}

Soil degradation has been identified as one of the most serious problems that threaten the sustainability of agriculture in Ethiopia. In an effort to address these problems the basic paradigm and approach to soil and water conservation has itself involved over time. The main objective of this study was to assess the current level of community participation in soil water conservation, explain the root cause of participatory soil water conservation problem, the effectiveness of soil water conservation to reduce soil erosion. To achieve the objective of the study, Researcher used focus group discussion, interview, and questionnaire and object observation. To collect data for the reason behind using of descriptive method is to get awareness and perception of respondents on participating of soil water conservation clearly. The investigator selects five kebele. Among the five clusters found in the woreda, totally 75 respondents were selected from respective kebeles. The major cause of soil erosion was found to be low population pressure, over grazing and unwise utilization of land which could result from deforestation and small land holding size. To different erosion controlling measures such as terracing, traditional water way, grass strip and planting trees have been implemented by farmers in the study area. However, the efforts made by farmers to control soil erosion were found to be in constant in efficient. The study identified that indigenous SWC technologies applied by farmers included physical biological management measures. The majority of respondent farmers participated in soil water conservation. Farmers well understood the results of sever vegetation cover and grass, structural, soil conservation majors practiced in study area included cut off, soil bunds, water ways, check dam. In the study area same SWC are indigenous like traditional stone bund, terracing, crop rotation. Modern SWC are also soil bund, cut off drain, planting was participated by community. The study shows that existence of soil water conservation in study area was identified by indicators like existence of gullies, reduction in soil capacity to grow crops and prevalence of barren land. The major cause soil erosion was found human population, poor farming practice, over cultivation and improper utilization of land which could result from deforestation and small land holding size. Regarding the awareness and perception of the community most farmers were aware of crop rotation following, terracing construction and planting trees But, because of different factors affecting to implement them include education, lack of training, small land holding size and socio-economic problem.

\subsection{Recommendation}

$>$ Educating farmers have positive impact on the implementation of SWC measures. So, it is important for farmers to get at least basic education through adult education program to help them receive and implement newly introduced SWC technologies.

$>$ The degradation depletion of soil, water and plants affects the lively hood of community because of this community must participate soil water conservation practice to solve the problem.

$>$ The lasting solutions to the problem of soil erosion should include minimizing population pressure and development of the other sectors of economy and involvement of the local people.

$>$ The traditional and new SWC technique which is in practice now should be strengthened. This may also include the involvement of individuals, community and inter Village Corporation.

$>$ Community based area closures and natural forests could be protected and managed. 


\section{References}

Abate Shiferew. (2011). Estimating soil lose rate for soil conservation planning in the Brenna woreda south wolo high lands, Ethiopia. Journals of Sustainable Development in Africa, (2011).

Aberabirhanu. (2003). Facture influencing the adaption of soil and water conservation practice in North West Ethiopia.

Abhijit Naik. (2011). Cause and consequence of global warming, buzzle.com http:www. Buzzle.com/articles that what cause global warning.htmi.Naik, Abhijit, (2001).

Addisa Banji Olalere. (2013). An assessment of participation of rural women in community Based Development Activities In osun state, Nigeria.

Akliluamsalu and D. J. Graaff. (2007). Determinants of adaption and continues one terraces for soil and water conservation in an Ethiopian highland water shade Ecological economics.

Alemu Mekonen. (2000). Hand Book on vetiver grass technology: From propagation to utilization for Ethiopia. GTZ, south Gondar, Ethiopia. Alexander Imam and Tamar consulting. 2006 soil erosion in England.

Amsalu Aklilu, Graaff, J. D. (2004). Farmers views of soil erosion problems and their conservation knowledge at Berasa water shade, Centeral highlands Ethiopia.

Bandara, D. and Thiruchelvan. (2008). Factors affecting the choice of soil conservation practice Adapted by Potato farmers in Sri lanka.

Baral, N. and Gautam, R. (2007). Socio-economic perspective on the conservation of critically endangered Vulture in south Asia.

Benin, S. and Pender, J. (2003). Policies for sustainable land management in East Africa highlands summary of peppers and proceedings. Conference. Addis Ababa.

Ethiopian Mapping Agency. (2018).

Kurabas Kebele Adminstrative Office. (2020).

Takussa Woreda Adminstrative Office. (2020).

Walles cause option problem.ImamAlexander@SOSwanky in stagrmphotos I view your images or brands consultants Imam Alexander Newyork missing Tamar 2006.Soil erosion walls causes option problem. 